\title{
Publisher Correction to: A Green Approach: Evaluation of Combretum indicum (Cl) Leaf Extract as an Eco-friendly Corrosion Inhibitor for Mild Steel in $1 \mathrm{M} \mathrm{HCl}$
}

\author{
Pavithra S. Neriyana ${ }^{1,2} \cdot$ Vijaya D . P. Alva $^{1,2}$
}

Published online: 23 November 2020

(C) The Tunisian Chemical Society and Springer Nature Switzerland AG 2020

\section{Publisher Correction to: Chemistry Africa https://doi.org/10.1007/s42250-020-00190-z}

In the original version of this article unfortunately column six and seven in Table 2 were wrong due to typesetting mistakes.

The original article has been corrected.

The original article can be found online at https://doi.org/10.1007/ s42250-020-00190-z.

Vijaya D . P. Alva

alvavijaya@gmail.com

1 Department of Chemistry, Shree Devi Institute of Technology, Kenjar, Mangalore, Karnataka 574142, India

2 Affiliated to Visvesvaraya Technological University, Belagavi, Karnataka, India 